\title{
Twist and Snail/Slug Expression in Oropharyngeal Squamous Cell Carcinoma in Correlation With Lymph Node Metastasis
}

\author{
YOON AH CHO ${ }^{1,2}$, EUN KYUNG KIM ${ }^{1}$, BYOUNG CHUL CHO ${ }^{3}$, YOON WOO $\mathrm{KOH}^{4}$ and SUN OCH YOON ${ }^{1}$ \\ ${ }^{1}$ Department of Pathology, Yonsei University College of Medicine, Severance Hospital, Seoul, Republic of Korea; \\ ${ }^{2}$ Department of Pathology and Translational genomics, Samsung Medical Center, Seoul, Republic of Korea; \\ ${ }^{3}$ Yonsei Cancer Center, Division of Medical Oncology, \\ Yonsei University College of Medicine, Severance Hospital, Seoul, Republic of Korea; \\ ${ }^{4}$ Department of Otorhinolaryngology, Yonsei University College of Medicine, \\ Severance Hospital, Seoul, Republic of Korea
}

\begin{abstract}
Background/Aim: Oropharyngeal squamous cell carcinoma (OPSCC) could be clinically undetectable despite the relatively large size of lymph node metastases. Here, we aimed to elucidate the correlation of pl6 expression with epithelial-to-mesenchymal transition (EMT) markers. Patients and Methods: Radically resected 121 OPSCC and 270 non-OPSCC tissue samples were included in the analysis, and p16, Twist, and Snail/Slug immunohistochemistry was performed. Results: Compared to non-OPSCCs, OPSCCs were significantly associated with lymphovascular invasion, lymph node metastasis, larger maximal diameter of metastatic foci in the lymph nodes, and p16 expression. In addition, p16 expression correlated with high Twist and Snail/Slug expression. Conclusion: Expression of EMT markers, such as Twist and Snail/Slug, is related to p16 expression in OPSCC. This might indicate that HPV infection in OPSCCs alters the expression of EMT markers and results in metastases.
\end{abstract}

Squamous cell carcinoma is the most common histologic subtype of head and neck cancer and accounts for 95\% of all cases (1). Head and neck squamous cell carcinomas (HNSCCs) exhibit different characteristics depending on the anatomical location. Most oropharyngeal SCCs (OPSCC) are related to human papilloma virus (HPV) infection $(2,3)$. OPSCC is frequently characterized by lymph node

Correspondence to: Sun Och Yoon, MD, Ph.D., Department of Pathology, Severance Hospital, Yonsei University College of Medicine, Yonsei-ro 50-1, Seodaemun-gu, Seoul, 03722, Republic of Korea. Tel: +82 222281763, Fax: +82 23620860, e-mail: revita@naver.com

Key Words: Oropharyngeal squamous cell carcinoma, head and neck squamous cell carcinoma, tumor budding, epithelial-tomesenchymal transition, lymph node metastasis. metastasis before the detection of the primary tumor (4-6). Although lymph node metastases are large, primary OPSCC tumors are smaller and may be clinically undetectable (4, 5). As a result, a "No tumor identified" (T0) stage, was introduced in the American Joint Committee on Cancer (AJCC) 8th edition for HPV-positive oropharyngeal cancer (7). However, the exact mechanism underlying this paradoxical phenomenon is not clearly understood. Considering that lymph node metastasis is a major risk factor related to poor outcomes in OPSCC patients, identification of the underlying mechanism associated with HPV infection may reveal potential strategies for managing lymph node metastasis in these patients.

Epithelial-to-mesenchymal transition (EMT) is known to be involved in tumor invasion and metastasis $(8,9)$. Repression of E-cadherin and induction of $\mathrm{N}$-cadherin are regulated by transcription factors, such as Snail and Twist (10). The expression of Twist and Snail, which are associated with tumor size, distant metastasis, and patient survival, has been reported in various cancers, such as breast cancer, pharyngeal squamous cell carcinoma, and colorectal carcinoma (11-14). According to several studies, EMT might be associated with tumor budding (15-17).

In this study, we investigated the relationship among p16 expression, EMT markers, such as Twist and Snail, and tumor bud formation in the context of lymph node metastasis in OPSCC.

\section{Patients and Methods}

Patient selection and clinical information. Tissue specimens from 121 consecutive patients with OPSCC that underwent curative surgical resection from 2005 to 2012 at the Severance Hospital Seoul, Republic of Korea, were used in this study. In addition, 270 consecutive non-OPSCC specimens were included as a control group. For accurate evaluation of immunohistochemistry (IHC), exclusion criteria were as follows: decalcified specimens, too small 
Table I. Characteristic features of OPSCC and non-OPSCC.

\begin{tabular}{|c|c|c|c|c|c|c|c|}
\hline \multirow{3}{*}{$\begin{array}{l}\text { Category } \\
\text { Gender }\end{array}$} & \multirow{3}{*}{$\begin{array}{l}\text { Variables } \\
\text { Female }\end{array}$} & \multirow{3}{*}{$\begin{array}{c}\begin{array}{c}\text { No. of cases } \\
(\mathrm{n}=391)\end{array} \\
97\end{array}$} & \multicolumn{4}{|c|}{ Anatomical site } & \multirow{3}{*}{$\begin{array}{r}p \text {-Value } \\
0.011\end{array}$} \\
\hline & & & \multicolumn{2}{|c|}{$\begin{array}{c}\text { OPSCC (\%) } \\
\quad(\mathrm{n}=121)\end{array}$} & \multicolumn{2}{|c|}{$\begin{array}{l}\text { Non-OPSCC }(\%) \\
\qquad(\mathrm{n}=270)\end{array}$} & \\
\hline & & & 20 & $(16.5)$ & 77 & $(28.5)$ & \\
\hline & Male & 294 & 101 & $(83.5)$ & 193 & (71.5) & \\
\hline \multirow[t]{2}{*}{ Age (year) } & $<58$ & 190 & 57 & $(47.1)$ & 133 & $(49.3)$ & 0.694 \\
\hline & $\geq 58$ & 201 & 64 & $(52.9)$ & 137 & $(50.7)$ & \\
\hline \multirow[t]{3}{*}{ Smoking } & Never smoker & 151 & 38 & $(31.4)$ & 113 & (41.9) & 0.107 \\
\hline & Ex-smoker & 80 & 25 & (20.7) & 55 & (20.4) & \\
\hline & Current smoker & 160 & 58 & $(47.9)$ & 102 & $(37.7)$ & \\
\hline \multirow[t]{2}{*}{ LVI } & Negative & 315 & 81 & $(66.9)$ & 234 & (86.7) & $<0.001$ \\
\hline & Positive & 76 & 40 & $(33.1)$ & 36 & (13.3) & \\
\hline \multirow[t]{2}{*}{ Perineural invasion } & Negative & 337 & 111 & (91.7) & 226 & (83.7) & 0.033 \\
\hline & Positive & 54 & 10 & $(8.3)$ & 44 & (16.3) & \\
\hline \multirow[t]{2}{*}{ Pathologic T stage } & pT1-2 & 321 & 101 & $(83.5)$ & 220 & $(815)$ & 0.635 \\
\hline & pT3-4 & 70 & 20 & $(16.5)$ & 50 & $(18.5)$ & \\
\hline \multirow[t]{2}{*}{ Tumor budding ${ }^{a}$} & Low & 226 & 66 & $(55.0)$ & 160 & (61.3) & 0.245 \\
\hline & High & 155 & 54 & $(45.0)$ & 101 & $(38.7)$ & \\
\hline \multirow[t]{2}{*}{ LNM } & Absent & 172 & 23 & $(19.0)$ & 149 & $(55.2)$ & $<0.001$ \\
\hline & Present & 219 & 98 & $(81.0)$ & 121 & (44.8) & \\
\hline \multirow{3}{*}{$\begin{array}{l}\text { Maximum size of metastatic foci }(\mathrm{cm})^{b} \\
\text { p16 IHC }\end{array}$} & & 168 & \multicolumn{2}{|c|}{$2.38 \pm 1.08$} & \multicolumn{2}{|c|}{$1.66 \pm 1.57$} & 0.001 \\
\hline & Negative & 269 & 29 & $(24.0)$ & 240 & $(88.9)$ & $<0.001$ \\
\hline & Positive & 122 & 92 & $(76.0)$ & 30 & (11.1) & \\
\hline
\end{tabular}

OPSCC: Oropharyngeal squamous cell carcinoma; IHC: immunohistochemistry; LVI: lymphovascular invasion; LNM: lymph node metastasis.



sample size, cases with preoperative neoadjuvant therapy or those with inadequate clinical information.

Clinicopathologic factors, including patient's age, sex, and tumor size, were obtained from medical records. Pathologic factors, including lymphovascular invasion, perineural invasion, pathologic staging according to the 7th AJCC criteria (18), and tumor classification by the World Health Organization system (19), were determined via slide reviews by two pathologists (Y.A. Cho and S.O. Yoon). Resection margin status was classified into R0 resected and non-R0 resected cases. R0 resected cases, which made up $76.1 \%$ (300) of 391 cases were defined as those with microscopically negative resection margins.

Survival analyses was performed for R0 cases with completely resected tumors, considering the negative effect of the positive resection margin on patient survival (18). Overall survival (OS) was measured from the date of initial diagnosis to that of death or the last follow-up visit. Progression-free survival (PFS) was measured from the date of initial diagnosis to that of disease progression, defined as cancer recurrence, continuance of stable disease/partial remission/progressive disease without complete remission, or cancer-related death during the study period. The median follow-up period was 37.1 months (range=0.8-99.6 months). This study was approved by the Institutional Review Board of Severance Hospital (4-2015-0954).

Tissue microarray preparation. Formalin-fixed and paraffinembedded tissue sections were prepared and stained with hematoxylin and eosin $(H \& E)$. Representative tumor areas were selected and confirmed by inspection under a microscope and used for tissue microarray construction. Two or three different representative areas per case were selected; core tissues $(3 \mathrm{~mm}$ diameter) were obtained from individual tissue blocks (donor blocks) and arranged in recipient paraffin blocks (tissue array blocks) using a trephine apparatus.

IHC and interpretation. IHC was performed using a Ventana Bench Mark XT autostainer (Ventana Medical Systems, Tucson, AZ, USA) according to the manufacturer's instructions. Primary antibodies for p16 (ready to use; Ventana), Twist (dilution 1:200; Abcam, Cambridge, UK), and Snail/Slug (dilution 1:200; Abcam) were used.

Twist and Snail/Slug IHC expression was analyzed using the semi-quantitative $\mathrm{H}$-score method, which yields a possible score range of 0-300 (20) obtained by multiplying the dominant nuclear staining intensity score ( 0 , no staining; 1 , weak or barely detectable nuclear staining; 2 , intermediate brown nuclear staining; 3 , strong dark brown nuclear staining) with the percentage (0-100\%) of positive cells. Conventionally accepted criteria were used for $\mathrm{p} 16$ IHC, wherein positivity was defined as the presence of strong and diffused nuclear and cytoplasmic staining in $>70 \%$ of HNSCC cells. All other staining patterns were scored as negative (21).

Assessment of tumor budding in HNSCC. Representative slides of 391 HNSCC specimens were reviewed for tumor budding (Figure 1). However, H\&E slides for 10 cases, one OPSCC and nine nonOPSCCs, were not available for tumor budding evaluation. Tumor budding is defined as the presence of single carcinoma cells or a small cluster of cells ( $\leq 5$ cells) located at the invasive front of neoplastic epithelial tumors (22). Tumor budding was evaluated in 


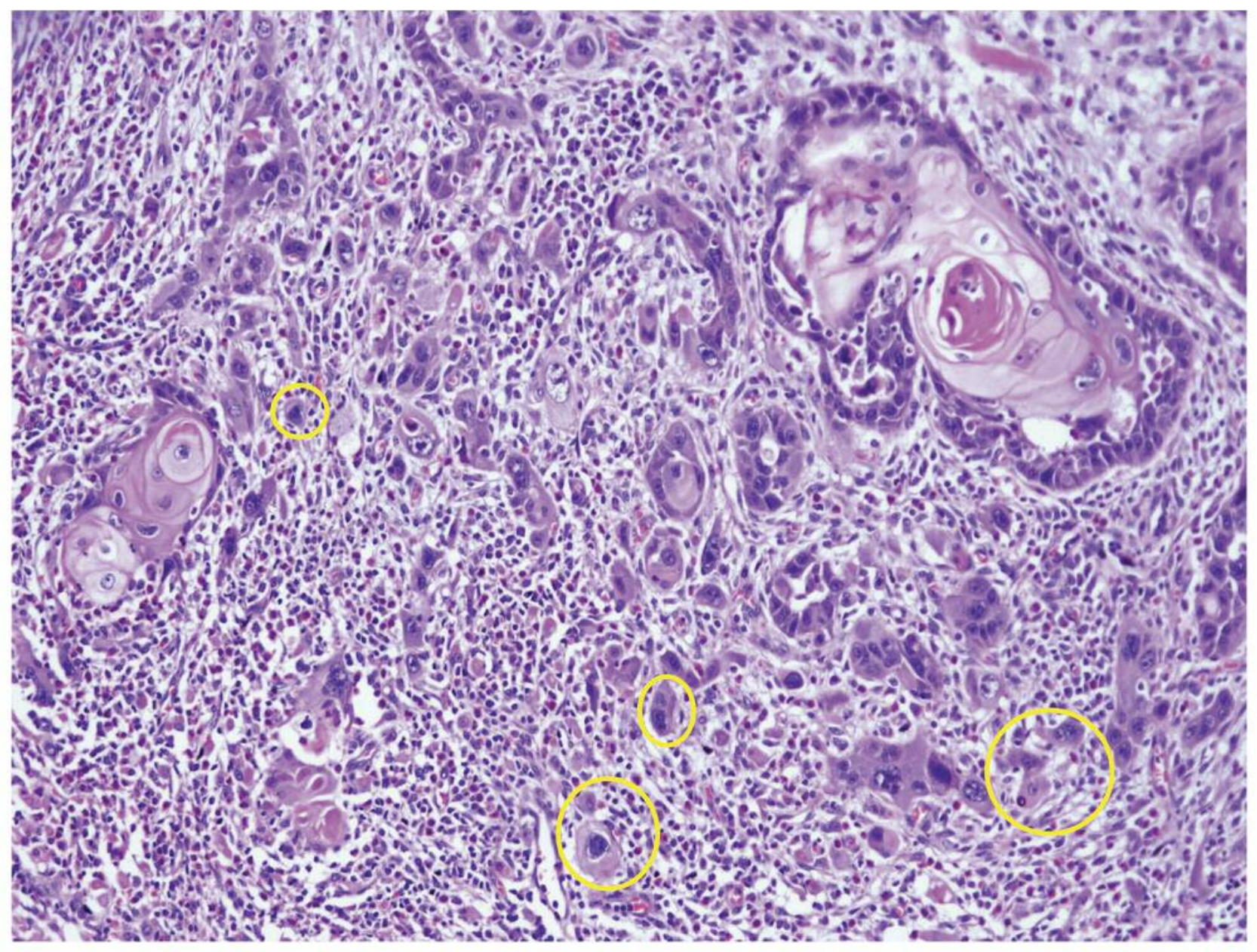

Figure 1. Tumor budding in HNSCC. Tumor budding is defined as the presence of single carcinoma cells or a small cluster of cells ( $\leq 5$ cells) located at the invasive front of neoplastic epithelial tumors.

the areas of highest cell density under high magnification $(400 x)$ (23). Cases with five or more buds were grouped as "high tumor budding" and those with less than five buds were grouped as "low tumor budding," as previously described (22).

Statistical analysis. The chi-square test was used to analyze the significance of differences among the examined variables. The Student's $t$-test was used for comparing variables, such as maximum diameter of lymph node metastasis. A two-sided $p<0.05$ was considered statistically significant. The Kaplan-Meier method was used to analyze survival rates, and differences were compared using the log-rank test. Statistical analyses were performed using IBM SPSS 22 software for Windows (IBM Corp, Somers, NY, USA).

\section{Results}

Clinicopathologic characteristics of OPSCC in terms of lymph node metastasis. OPSCC showed significantly different clinical characteristics from non-OPSCCs in terms of lymph node metastasis (Table I). OPSCCs were significantly associated with lymphovascular invasion $(p<0.001)$, lymph node metastasis $(p<0.001)$, and larger maximal diameter of metastatic foci than non-OPSCCs $(p=0.001$; Table I). As expected, OPSCCs were more associated with $\mathrm{p} 16$ positivity than non-OPSCCs, as shown by IHC $(p<0.001$; Table I).

Clinicopathologic characteristics of OPSCCs in conjunction with p16 IHC status. High tumor budding ( $>5$ buds) seemed to be more frequently identified in p16-positive OPSCCs than in p16-negative OPSCCs in IHC ( $p=0.015$; Table II). No significant correlation was observed between p16 positivity and other clinicopathologic variables, such as lymph node metastasis. Furthermore, no significant difference in clinicopathologic features associated with p16 positivity was reported for non-OPSCC (Table III). 
Table II. Clinicopathologic characteristics of OPSCC according to p16 IHC status.

\begin{tabular}{|c|c|c|c|c|c|c|c|}
\hline \multirow{3}{*}{$\begin{array}{l}\text { Category } \\
\text { Gender }\end{array}$} & \multirow{3}{*}{$\begin{array}{l}\text { Variables } \\
\text { Female }\end{array}$} & \multirow{3}{*}{$\begin{array}{c}\begin{array}{c}\text { No. of cases } \\
(\mathrm{n}=121)\end{array} \\
20\end{array}$} & \multicolumn{4}{|c|}{ p16 IHC status } & \multirow{3}{*}{$\begin{array}{r}p \text {-Value } \\
0.567\end{array}$} \\
\hline & & & \multicolumn{2}{|c|}{$\begin{array}{c}\text { Positive }(\%) \\
\quad(\mathrm{n}=92)\end{array}$} & \multicolumn{2}{|c|}{$\begin{array}{l}\text { Negative }(\%) \\
\quad(n=29)\end{array}$} & \\
\hline & & & 14 & $(15.2)$ & 6 & $(20.7)$ & \\
\hline & Male & 101 & 78 & $(84.8)$ & 23 & (79.3) & \\
\hline \multirow[t]{2}{*}{ Age (year) } & $<58$ & 57 & 43 & $(46.7)$ & 14 & $(48.3)$ & 0.885 \\
\hline & $\geq 58$ & 64 & 49 & $(53.3)$ & 15 & $(51.7)$ & \\
\hline \multirow[t]{3}{*}{ Smoking } & Never smoker & 38 & 32 & $(34.8)$ & 6 & $(20.7)$ & 0.184 \\
\hline & Ex-smoker & 25 & 16 & $(17.4)$ & 9 & $(31.0)$ & \\
\hline & Current smoker & 58 & 44 & $(47.8)$ & 14 & $(48.3)$ & \\
\hline \multirow[t]{2}{*}{ LVI } & Negative & 81 & 61 & $(66.3)$ & 20 & $(69.0)$ & 0.791 \\
\hline & Positive & 40 & 31 & $(33.7)$ & 9 & $(31.0)$ & \\
\hline \multirow[t]{2}{*}{ Perineural invasion } & Negative & 111 & 86 & $(93.5)$ & 25 & $(86.2)$ & 0.249 \\
\hline & Positive & 10 & 6 & $(6.5)$ & 4 & (13.8) & \\
\hline \multirow[t]{2}{*}{ Pathologic T stage } & pT1-2 & 101 & 77 & $(83.7)$ & 24 & $(82.8)$ & $>0.999$ \\
\hline & pT3-4 & 20 & 15 & $(16.3)$ & 5 & $(17.2)$ & \\
\hline \multirow[t]{2}{*}{ Tumor budding status ${ }^{\mathrm{a}}$} & Low & 66 & 45 & $(48.9)$ & 21 & $(75.0)$ & 0.015 \\
\hline & High & 54 & 47 & $(51.1)$ & 7 & $(25.0)$ & \\
\hline \multirow[t]{2}{*}{ LNM } & Absent & 23 & 19 & $(20.7)$ & 4 & $(13.8)$ & 0.412 \\
\hline & Present & 98 & 73 & $(79.3)$ & 25 & $(86.2)$ & \\
\hline Maximum diameter of metastatic foci $(\mathrm{cm})^{\mathrm{b}}$ & & 76 & \multicolumn{2}{|c|}{$2.21 \pm 1.47$} & \multicolumn{2}{|c|}{$2.44 \pm 0.90$} & 0.513 \\
\hline
\end{tabular}

OPSCC: Oropharyngeal squamous cell carcinoma; IHC: immunohistochemistry; LVI: lymphovascular invasion; LNM: lymph node metastasis. aEvaluated in 120 cases; bevaluated in 56 p16-positive and 20 p16-negative cases. Results are expressed as mean \pm standard deviation.

Table III. Clinicopathologic characteristics of 270 non-OPSCCs according to p16 IHC status.

\begin{tabular}{|c|c|c|c|c|c|c|c|}
\hline \multirow{3}{*}{$\begin{array}{l}\text { Category } \\
\text { Sex }\end{array}$} & \multirow{3}{*}{$\begin{array}{l}\text { Variables } \\
\text { Female }\end{array}$} & \multirow{3}{*}{$\begin{array}{l}\text { No. of cases } \\
\qquad(\mathrm{n}=270)\end{array}$} & \multicolumn{4}{|c|}{ p16 IHC status } & \multirow{3}{*}{$\begin{array}{r}p \text {-Value } \\
0.294\end{array}$} \\
\hline & & & \multicolumn{2}{|c|}{$\begin{array}{l}\text { Positive }(\%) \\
\quad(\mathrm{n}=30)\end{array}$} & \multicolumn{2}{|c|}{$\begin{array}{c}\text { Negative }(\%) \\
(\mathrm{n}=240)\end{array}$} & \\
\hline & & & 11 & $(36.7)$ & 66 & $(27.5)$ & \\
\hline & Male & 193 & 19 & $(63.3)$ & 174 & $(72.5)$ & \\
\hline \multirow[t]{2}{*}{ Age (yrs) } & $<58$ & 133 & 19 & $(63.3)$ & 114 & $(47.5)$ & 0.102 \\
\hline & $\geq 58$ & 137 & 11 & $(36.7)$ & 126 & $(52.5)$ & \\
\hline \multirow[t]{3}{*}{ Smoking } & Never smoker & 113 & 15 & $(50.0)$ & 99 & $(40.8)$ & 0.141 \\
\hline & Ex-smoker & 55 & 2 & (6.7) & 53 & $(22.1)$ & \\
\hline & Current smoker & 102 & 13 & $(43.3)$ & 89 & $(37.1)$ & \\
\hline \multirow[t]{2}{*}{ LVI } & Negative & 234 & 26 & $(86.7)$ & 208 & (86.7) & $>0.999$ \\
\hline & Positive & 36 & 4 & (13.3) & 32 & (13.3) & \\
\hline \multirow{2}{*}{ Perineural invasion } & Negative & 226 & 23 & (76.7) & 203 & (84.6) & 0.294 \\
\hline & Positive & 44 & 7 & (23.3) & 37 & (15.4) & \\
\hline \multirow[t]{2}{*}{ Pathologic T stage } & pT1-2 & 220 & 24 & $(80.0)$ & 196 & (81.7) & 0.825 \\
\hline & pT3-4 & 50 & 6 & $(20.0)$ & 44 & (18.3) & \\
\hline \multirow[t]{2}{*}{ Tumor budding status* } & Low & 160 & 19 & $(63.3)$ & 141 & $(61.0)$ & 0.808 \\
\hline & High & 101 & 11 & $(36.7)$ & 90 & $(39.0)$ & \\
\hline \multirow[t]{2}{*}{ LNM } & Absent & 149 & 16 & $(53.3)$ & 133 & $(55.4)$ & 0.829 \\
\hline & Present & 121 & 14 & $(46.7)$ & 107 & $(44.6)$ & \\
\hline Maximal size of metastatic foci $(\mathrm{cm})^{* *}$ & & 92 & \multicolumn{2}{|c|}{$1.50 \pm 1.17$} & \multicolumn{2}{|c|}{$2.70 \pm 3.50$} & 0.203 \\
\hline
\end{tabular}

OPSCC: Oropharyngeal squamous cell carcinoma; IHC: immunohistochemistry; LVI: lymphovascular invasion; LNM: lymph node metastasis.

*Evaluated in 261 cases; **Evaluated in 12 p16 IHC positive and 80 p16 IHC negative cases. Result is displayed as mean \pm standard deviation. 
A

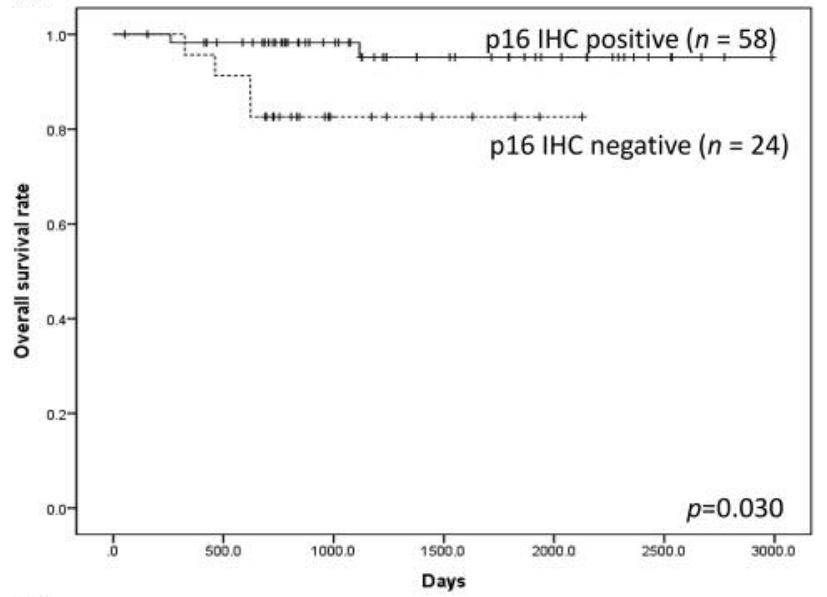

C

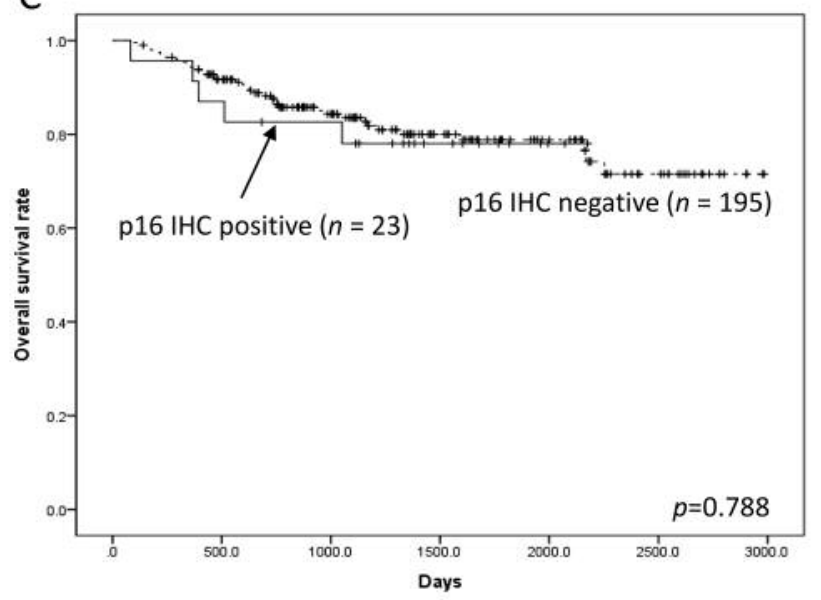

B

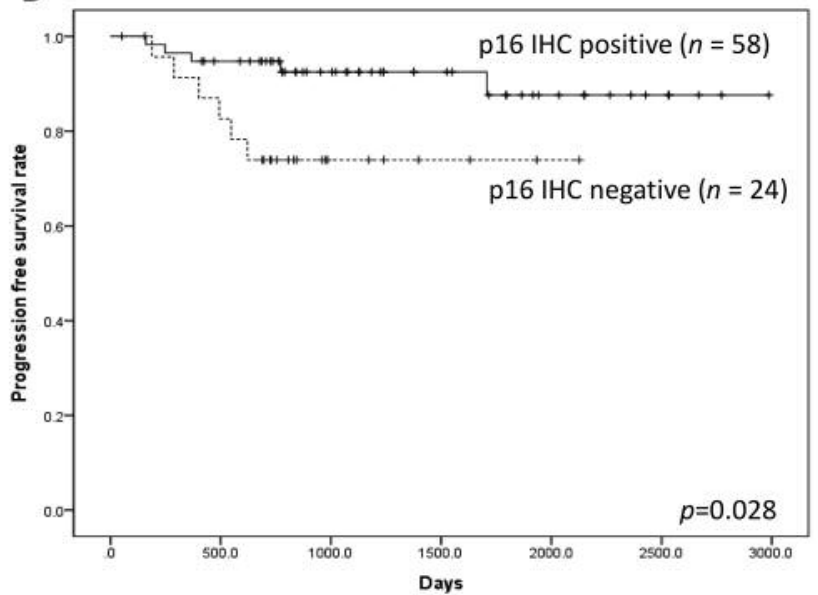

D

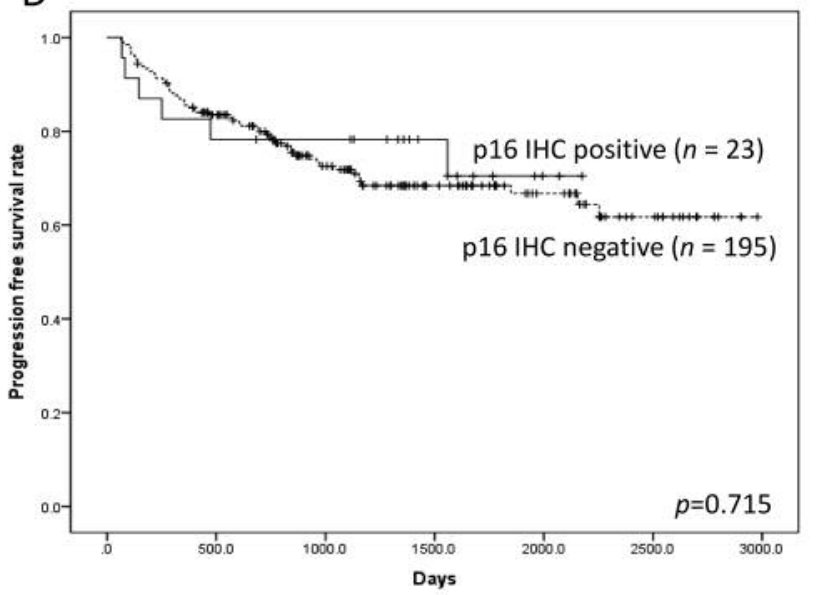

Figure 2. Kaplan-Meier analysis of R0-resected OPSCC and non-OPSCC patients. In the analysis of 82 RO resected OPSCC cases, p16 IHC positive cases showed $(A)$ longer overall survival $(O S ; p=0.030)$ and $(B)$ superior progression-free survival $(P F S)$ than the p16 IHC negative cases $(p=0.028)$. No significant difference associated with the p16 IHC status was observed in non-OPSCC $(C)$ OS $(p=0.788)$ and $(D) P F S(p=0.715)$.

In a Kaplan-Meier analysis of 82 R0-resected OPSCCs, p16-positive cases showed significantly superior OS and PFS ( $p=0.030$ and 0.028, respectively; Figure 2A and 2B). However, 218 R0-resected non-OPSCCs showed no correlation with p16 positivity in terms of OS or PFS $(p=0.788$ and 0.715 , respectively; Figure $2 \mathrm{C}$ and $2 \mathrm{D})$.

Twist and Snail/Slug expression in HNSCCs. Twist and Snail/Slug IHC showed nuclear staining in all 121 OPSCC and 270 non-OPSCC cases. The intensity and proportion of Twist and Snail/Slug expression varied (Figures 3 and 4). Twist expression H-scores ranged from 0 to 145.5 and the median $\mathrm{H}$-score was 10 . H-scores $\geq 10$ were defined as 'high Twist expression' and H-scores $<10$ were defined as 'low Twist expression'. Snail/Slug H-scores ranged from 5 to 300 with a median $\mathrm{H}$-score of 147 . H-scores $\geq 147$ were defined as 'high Snail/Slug expression' and H-scores <147 were defined as 'low Snail/Slug expression'.

Twist and Snail/Slug expression status of OPSCCs in conjunction with p16 IHC status. All of the 391 tested HNSCCs were analyzed based on their association with anatomical sites and p16 IHC statuses. In all HNSCCs, high Twist expression was significantly correlated with p16 positive cases $(p<0.001$; Figure 5A). When analyzing all HNSCCs based on anatomical sites, high Twist expression was associated with p16-positive OPSCCs compared to those with p16 negativity $(p=0.020$; Figure 5B). Similar to OPSCCs, non-OPSCCs with p16 positivity were significantly correlated with high Twist expression than those with p16 negativity ( $p=0.004$; Figure $5 \mathrm{~B}$ ).

High Snail/Slug expression was also correlated with p16positive than p16-negative HNSCCs ( $p=0.001$; Figure 5C). 


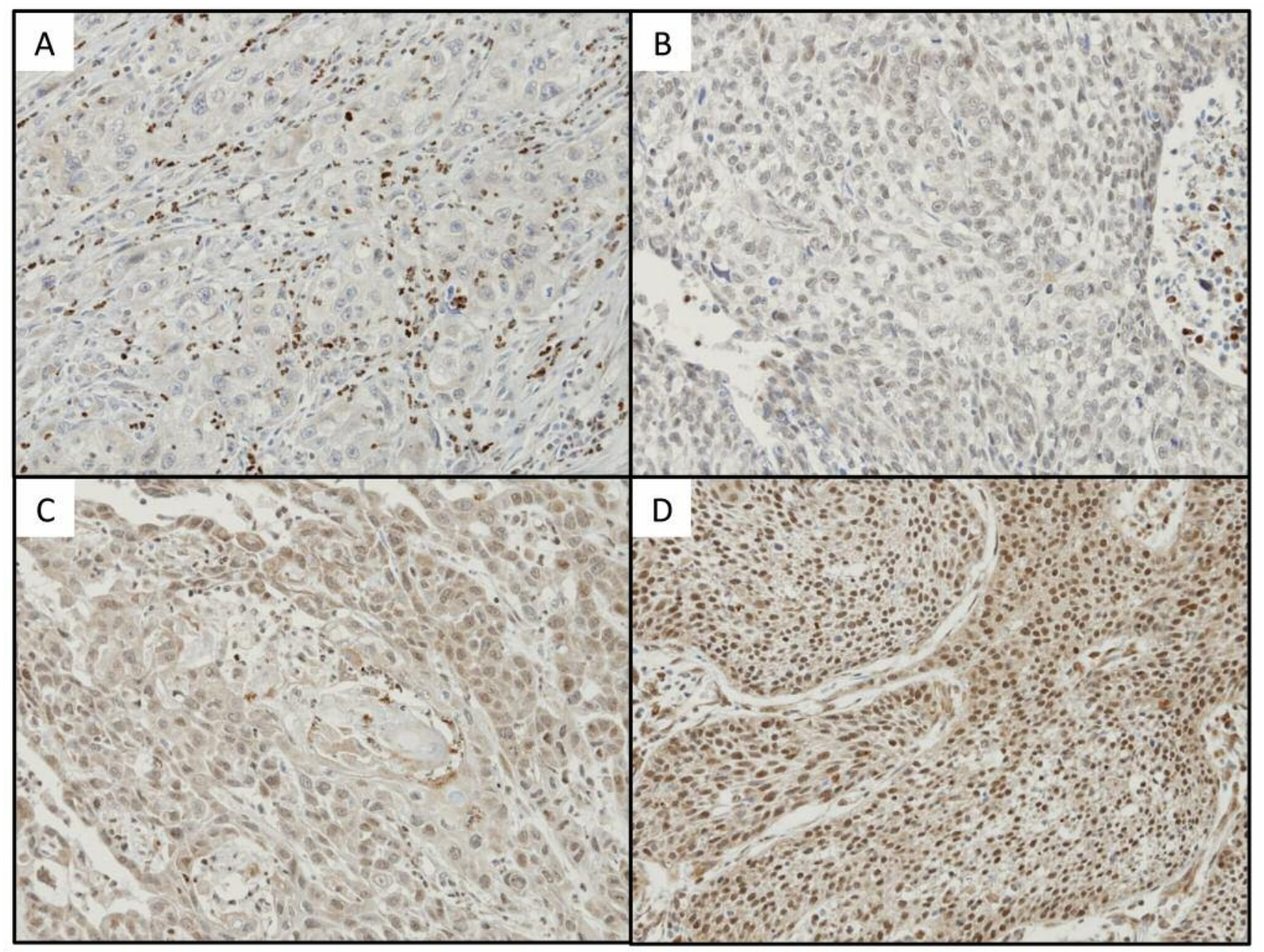

Figure 3. Twist protein expression via immunohistochemical staining in HNSCC. Twist immunohistochemical staining showed nuclear staining in HNSCC tissue samples. The expression level varied among the HNSCCs. Staining showed (A) negative, $(B)$ weak $(1+),(C)$ intermediate $(2+)$, and (D) strong (3+) intensities.

Similar to Twist expression, a higher proportion of high Snail/Slug expression was observed in p16-positive than p16-negative OPSCCs ( $p=0.023$; Figure 4D). However, no significant association was identified between Snail/Slug expression and 16 IHC status in non-OPSCCs $(p=0.342$; Figure 5D).

\section{Discussion}

OPSCC is known to be associated more frequently with HPV infection than HNSCCs of other sites (2,3), and HPV type 16 accounts for approximately $82 \%$ of all HPV genotypes in HPVassociated HNSCCs (24). IHC for p16 $6^{\mathrm{INK} 4 \mathrm{a}}$ expression was recently used as an HPV infection surrogate marker in routine HNSCC diagnosis $(21,25)$. This is based on the surmise that HPV infection induces p16 protein overexpression through uncontrolled cell cycle regulation in cancers $(26,27)$. In this study, we analyzed the clinicopathological variables that may be possibly related to lymph node metastasis and the expression of EMT markers in OPSCC and non-OPSCC samples in conjunction with the p16 expression status.

In the present study cohort, we observed that $76 \%$ of OPSCC cases were positive for p16 expression in IHC, suggestive of HPV infection. Furthermore, p16-positive OPSCCs showed favorable patient prognosis compared to p16-negative OPSCCs. In non-OPSCCs, the p16 status showed no significant association with patient prognosis. These findings were consistent with previous reports, as the HPV-associated OPSCCs, as determined with p16 positivity, showed more favorable patient outcomes $(21,28,29)$.

We noted that the clinicopathologic characteristics of OPSCCs were significantly different from those of non- 


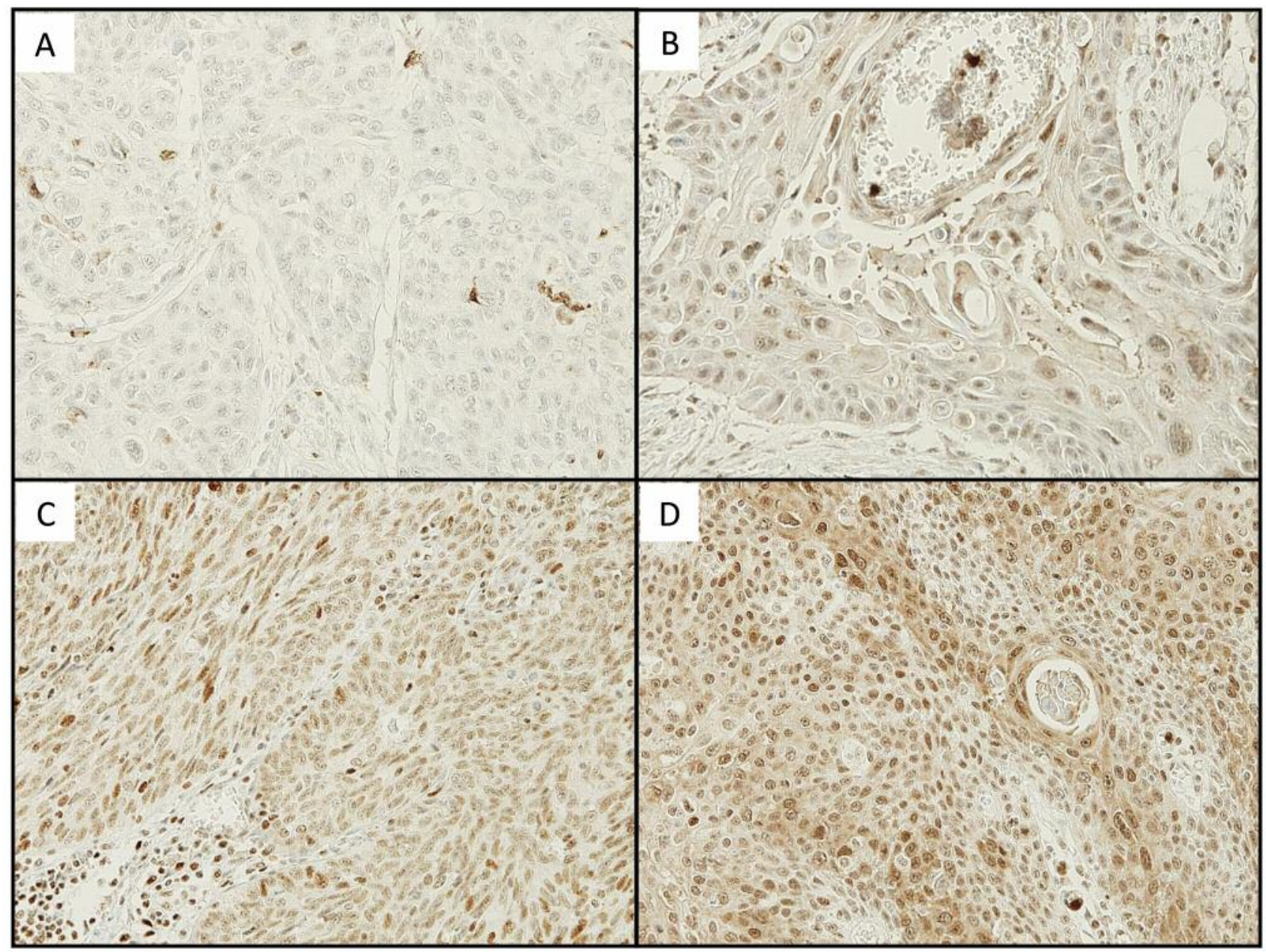

Figure 4. Snail/Slug protein expression via immunohistochemical staining in HNSCC. Snail/Slug immunohistochemical staining showed nuclear staining in HNSCC tissue samples. The expression level varied among the HNSCCs. Staining showed (A) negative, $(B)$ weak $(1+),(C)$ intermediate $(2+)$, and $(D)$ strong $(3+)$ intensities.

OPSCCs. Compared with non-OPSCCs, OPSCCs were significantly associated with lymphovascular invasion, lymph node metastasis, and larger maximal diameter of metastatic foci in lymph nodes, as well as with p16 positivity. These clinicopathologic findings are suggestive of the possible effect of HPV on lymph node metastasis in OPSCC. A recent study on OPSCC reported the correlation between cervical lymph node metastasis and HPV status, as determined using either p16 IHC or HPV in situ hybridization (30). However, no significant correlation was observed between p16 IHC status and factors such as lymphovascular invasion, lymph node metastasis, or maximum diameter of metastatic tumor foci in the OPSCC cases of the present cohort. Although HPV infection may be associated with the tumorigenesis of OPSCC (31), its role in tumor metastasis to lymph nodes seems confusing.
EMT, the process by which the cells lose epithelial features and acquire mesenchymal characteristics, increases the migratory and invasive properties of tumor cells (8-10). EMT markers, Snail1 and Snail2 (Slug), are encoded by SNAI1 and SNAI2 genes, respectively, and are involved in cell differentiation and survival. Snail1 is known as a poor prognosis factor related to treatment failure, while Snail2 is activated in metastatic HNSCC $(32,33)$. Twist is known to play a role in multiple stages of embryonic development and promote cancer stem cells and EMT $(33,34)$.

We observed that the expression of Twist and Snail/Slug was higher in the samples of p16-positive cases among all HNSCCs. In addition, p16-positive OPSCCs showed significantly higher Twist and Snail/Slug expression than p16negative OPSCCs. The limitation of this study is that the Twist staining level was generally low. Also, we used the Snail/Slug 
A

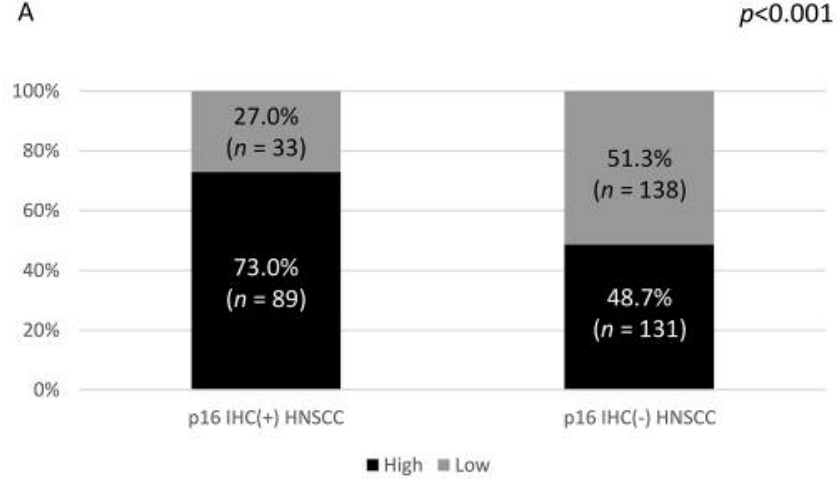

C

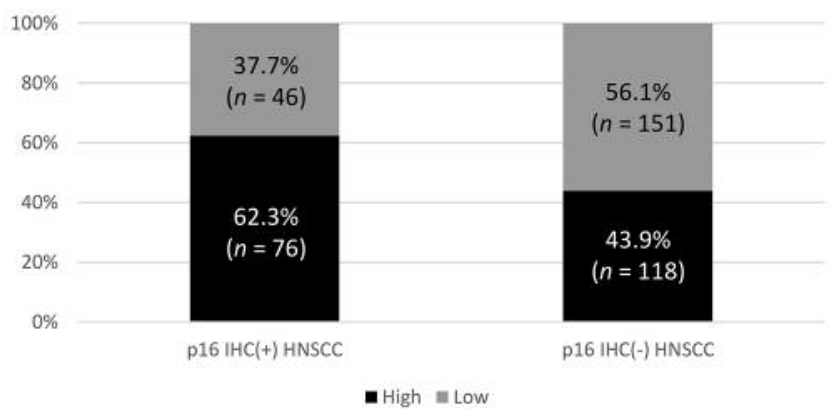

B

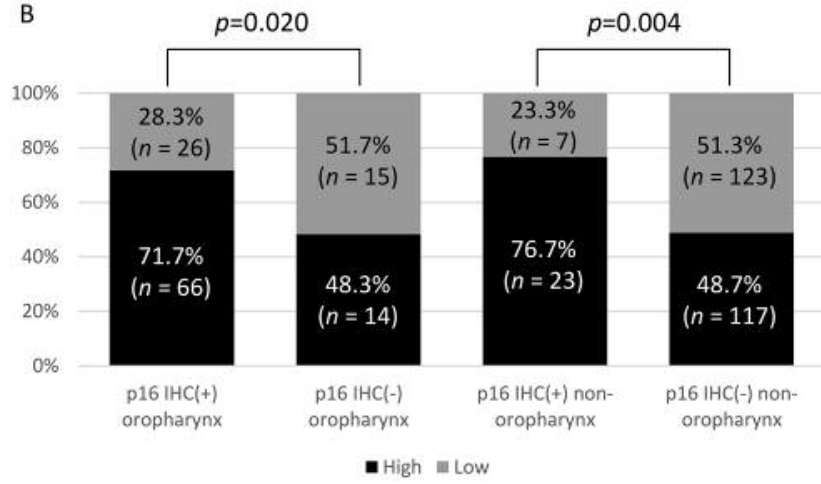

D

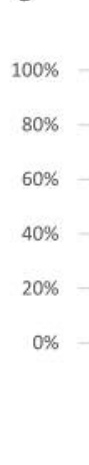

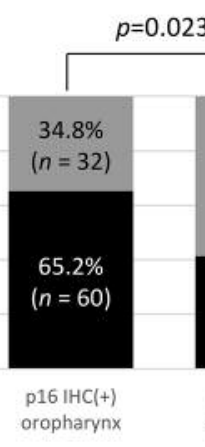

$=0.023$



oropharynx

- High $=$ Low

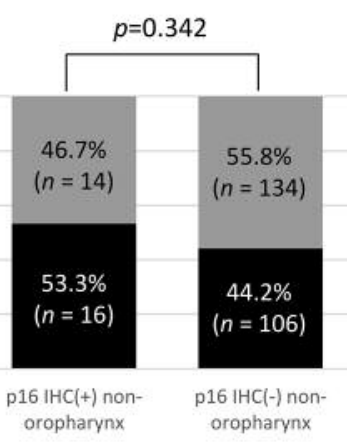

Figure 5. Twist and Snail/Slug protein expression status with respect to anatomical sites and p16 IHC expression. (A) Twist expression status in conjunction with p16 IHC status in HNSCC. High Twist expression level was statistically correlated with p16 IHC positive HNSCC. ( $p<0.001)(B)$ A higher proportion of high Twist expression statuses was seen in $p 16$ IHC positive than negative OPSCCs and non-OPSCCs ( $p=0.020$ and $p=0.004$, respectively) (C) p16-positive HNSCCs revealed higher portion of high Snail/Slug expression than p16-negative HNSCCs $(p=0.001)(D) p 16$ IHC positive OPSCCs correlated with high Snail/Slug expression compared to p16 IHC negative OPSCCs ( $p=0.023)$. No statistically significant correlation between Snail/Slug expression and p16 IHC status was found in non-OPSCCs $(p=0.342)$.

cocktail antibody for Snail detection, because we failed to observe adequate staining with several other antibodies.

Tumor budding is a well-known histological variable representative of EMT. Tumor budding is common in HNSCC. Several reports have described tumor budding to be EMT and as a prognostic factor in $\operatorname{HNSCC}(22,35,36)$. In this study, high tumor budding was significantly related to p16 positivity in OPSCCs. On the contrary, p16 IHC status was not related to tumor budding in non-OPSCCs. These findings suggest that EMT marker changes, as well as morphologic changes, can be related to the lymph node metastasis of OPSCCs.

In conclusion, expression of EMT markers, such as Twist and Snail/Slug, and formation of tumor buds are related to p16 expression in OPSCC. This indicates that HPV infection in OPSCCs may alter the expression of EMT markers such as Twist and Snail/Slug and lead to metastases, despite the relatively small tumor size. Although further in-depth studies are warranted, our findings may help to gain insights into the biology of HPV-positive OPSCCs for the early detection and management of lymph node metastasis during initial diagnosis and follow-up observation for tumor recurrence in patients with OPSCC.

\section{Conflicts of Interest}

The Authors have no conflicts of interest to declare regarding this study.

\section{Authors' Contributions}

Conception and design: Y.A.C., S.O.Y.; Development of methodology: Y.A.C., E.K.K.; Acquisition and analysis of data and drafting of the manuscript: Y.A.C., C.B.C., Y.W.K.; Analysis and interpretation of experimental data: Y.A.C., C.B.C., Y.W.K.; Writing, review, and/or revision of the manuscript: Y.A.C., S.O.Y.; Study supervision: S.O.Y. 


\section{Acknowledgements}

The study was supported by the Basic Science Research Program through the National Research Foundation of Korea (NRF), funded by the Ministry of Education (NRF-2015R1D1A1A09059399).

\section{References}

1 Chaturvedi AK, Anderson WF, Lortet-Tieulent J, Curado MP, Ferlay J, Franceschi S, Rosenberg PS, Bray F and Gillison ML: Worldwide trends in incidence rates for oral cavity and oropharyngeal cancers. J Clin Oncol 31(36): 4550-4559, 2013. PMID: 24248688. DOI: 10.1200/JCO.2013.50.3870

2 Feller L, Wood NH, Khammissa RA and Lemmer J: Human papillomavirus-mediated carcinogenesis and HPV-associated oral and oropharyngeal squamous cell carcinoma. Part 2: Human papillomavirus associated oral and oropharyngeal squamous cell carcinoma. Head Face Med 6: 15, 2010. PMID: 20633288. DOI: 10.1186/1746-160X-6-15

3 Hamilton D, Khan MK, O'Hara J and Paleri V: The changing landscape of oropharyngeal cancer management. J Laryngol Otol 131(1): 3-7, 2017. PMID: 27894364. DOI: 10.1017/S00 22215116009178

4 Begum S, Gillison ML, Ansari-Lari MA, Shah K and Westra WH: Detection of human papillomavirus in cervical lymph nodes: a highly effective strategy for localizing site of tumor origin. Clin Cancer Res 9(17): 6469-6475, 2003. PMID: 14695150.

5 de Braud $\mathrm{F}$ and al-Sarraf $\mathrm{M}$ : Diagnosis and management of squamous cell carcinoma of unknown primary tumor site of the neck. Semin Oncol 20(3): 273-278, 1993. PMID: 8503023.

6 Sessions RB PC, Cummings CW, Fredrickson JM, Harker LA, Krause CJ, Richardson MA and Schuller DE: Malignant cervical adenopathy. Mosby, New York, 1998, pp. 1737-1757.

7 Amin MB, Edge S, Greene F, Byrd DR, Brookland RK, Washington MK, Gershenwald JE, Compton CC, Hess KR, Sullivan DC, Jessup JM, Brierley JD, Gaspar LE, Schilsky RL, Balch CM, Winchester DP, Asare EA, Madera M, Gress DM and Meyer LR (eds.): AJCC cancer staging manual. Eight edition. Chicago, IL, USA, American Joint Committee on Cancer, Springer, 2017.

8 Thiery JP: Epithelial-mesenchymal transitions in tumour progression. Nat Rev Cancer 2(6): 442-454, 2002. PMID: 12189386. DOI: $10.1038 / \mathrm{nrc} 822$.

9 Kalluri R and Weinberg RA: The basics of epithelialmesenchymal transition. J Clin Invest 119(6): 1420-1428, 2009 PMID: 19487818 . DOI: 10.1172/jci39104.

10 Lamouille S, Xu J and Derynck R: Molecular mechanisms of epithelial-mesenchymal transition. Nat Rev Mol Cell Biol 15(3): 178-196, 2014. PMID: 24556840. DOI: 10.1038/ nrm3758.

11 Grzegrzolka J, Biala M, Wojtyra P, Kobierzycki C, Olbromski M, Gomulkiewicz A, Piotrowska A, Rys J, Podhorska-Okolow $\mathrm{M}$ and Dziegiel P: Expression of EMT markers SLUG and TWIST in breast cancer. Anticancer Res 35(7): 3961-3968, 2015. PMID: 26124343

12 Jouppila-Matto A, Narkio-Makela M, Soini Y, Pukkila M, Sironen R, Tuhkanen H, Mannermaa A and Kosma VM: Twist and snail expression in pharyngeal squamous cell carcinoma stroma is related to cancer progression. BMC Cancer 11: 350, 2011. PMID: 21834956. DOI: 10.1186/1471-2407-11-350.
13 Franci C, Gallen M, Alameda F, Baro T, Iglesias M, Virtanen I and Garcia de Herreros A: Snail1 protein in the stroma as a new putative prognosis marker for colon tumours. PLoS One 4(5): e5595, 2009. PMID: 19440385. DOI: 10.1371/journal.pone. 0005595.

14 Jung YS, Kato I and Kim HR: A novel function of HPV16E6/E7 in epithelial-mesenchymal transition. Biochem Biophys Res Commun 435(3): 339-344, 2013. PMID: 23628416. DOI: 10.1016/j.bbrc.2013.04.060

15 Kalluri R: EMT: when epithelial cells decide to become mesenchymal-like cells. J Clin Invest 119(6): 1417-1419, 2009. PMID: 19487817. DOI: 10.1172/jci39675

16 Mitrovic B, Schaeffer DF, Riddell RH and Kirsch R: Tumor budding in colorectal carcinoma: time to take notice. Mod Pathol 25(10): 1315-1325, 2012. PMID: 22790014. DOI: 10.1038/ modpathol.2012.94

17 Chaffer CL and Weinberg RA: A perspective on cancer cell metastasis. Science 331(6024): 1559-1564, 2011. PMID: 21436443. DOI: $10.1126 /$ science. 1203543

18 Edge SB and American Joint Committee on Cancer: AJCC cancer staging manual. 7th ed. New York; London, Springer, 2010.

19 El-Naggar AK, Chan JKC, Rubin Grandis J, Takata T, Slootweg PJ and International Agency for Research on Cancer: WHO classification of head and neck tumours, 4th Edition, Volume 9, IARC Publications, Lyon, France, 2017.

20 Park E, Park SY, Kim H, Sun PL, Jin Y, Cho SK, Kim K, Lee CT and Chung JH: Membranous insulin-like growth factor-1 receptor (IGF1R) expression is predictive of poor prognosis in patients with epidermal growth factor receptor (EGFR)-mutant lung adenocarcinoma. J Pathol Transl Med 49(5): 382-388, 2015. PMID: 26265685. DOI: 10.4132/jptm.2015.07.10

21 Ang KK, Harris J, Wheeler R, Weber R, Rosenthal DI, NguyenTan PF, Westra WH, Chung CH, Jordan RC, Lu C, Kim H, Axelrod R, Silverman CC, Redmond KP and Gillison ML: Human papillomavirus and survival of patients with oropharyngeal cancer. N Engl J Med 363(1): 24-35, 2010. PMID: 20530316. DOI: 10.1056/NEJMoa0912217

22 Attramadal CG, Kumar S, Boysen ME, Dhakal HP, Nesland JM and Bryne M: Tumor budding, EMT and cancer stem cells in T1-2/N0 oral squamous cell carcinomas. Anticancer Res 35(11): 6111-6120, 2015. PMID: 26504037.

23 Almangush A, Salo T, Hagstrom J and Leivo I: Tumour budding in head and neck squamous cell carcinoma - a systematic review. Histopathology 65(5): 587-594, 2014. PMID: 24897954. DOI: $10.1111 /$ his.12471

24 Lefevre M, Rousseau A, Rayon T, Dalstein V, Clavel C, BebyDefaux A, Pretet J-L, Soussan P, Polette M and Saint Guily JL: Epithelial to mesenchymal transition and HPV infection in squamous cell oropharyngeal carcinomas: The papillophar study. Br J Cancer 116(3): 362, 2017. PMID: 28072763. DOI: 10.1038/bjc.2016.434

25 Mirghani H, Casiraghi O, Amen F, He M, Ma XJ, Saulnier P, Lacroix L, Drusch F, Ben Lakdhar A, Saint Guily JL, Badoual C, Scoazec JY and Vielh P: Diagnosis of HPV-driven head and neck cancer with a single test in routine clinical practice. Mod Pathol 28(12): 1518-1527, 2015. PMID: 26403782. DOI: 10.1038/modpathol.2015.113

26 Tornesello ML, Perri F, Buonaguro L, Ionna F, Buonaguro FM and Caponigro F: HPV-related oropharyngeal cancers: from pathogenesis to new therapeutic approaches. Cancer Lett 351(2): 
198-205, 2014. PMID: 24971935. DOI: 10.1016/j.canlet. 2014.06.003

27 Moody CA and Laimins LA: Human papillomavirus oncoproteins: pathways to transformation. Nat Rev Cancer 10(8): 550-560, 2010. PMID: 20592731. DOI: $10.1038 / \mathrm{nrc} 2886$

28 Langendijk JA and Psyrri A: The prognostic significance of p16 overexpression in oropharyngeal squamous cell carcinoma: implications for treatment strategies and future clinical studies. Ann Oncol 21(10): 1931-1934, 2010. PMID: 20716626. DOI: 10.1093/annonc/mdq439

29 Lassen P, Eriksen JG, Hamilton-Dutoit S, Tramm T, Alsner J and Overgaard J: Effect of HPV-associated p16INK4A expression on response to radiotherapy and survival in squamous cell carcinoma of the head and neck. J Clin Oncol 27(12): 19921998, 2009. PMID: 19289615. DOI: 10.1200/jco.2008.20.2853

30 Amsbaugh MJ, Yusuf M, Cash E, Silverman C, Wilson E, Bumpous J, Potts K, Perez C, Bert R, Redman R and Dunlap N: Distribution of cervical lymph node metastases from squamous cell carcinoma of the oropharynx in the era of risk stratification using human papillomavirus and smoking status. Int J Radiat Oncol Biol Phys 96(2): 349-353, 2016. PMID: 27598805. DOI: 10.1016/j.ijrobp.2016.06.2450

31 Wiest T, Schwarz E, Enders C, Flechtenmacher C and Bosch FX: Involvement of intact HPV16 E6/E7 gene expression in head and neck cancers with unaltered p53 status and perturbed pRb cell cycle control. Oncogene 21(10): 1510-1517, 2002. PMID: 11896579 . DOI: 10.1038/sj.onc.1205214

32 Scanlon CS, Van Tubergen EA, Inglehart RC and D'Silva NJ: Biomarkers of epithelial-mesenchymal transition in squamous cell carcinoma. J Dent Res 92(2): 114-121, 2013. PMID: 23128109. DOI: $10.1177 / 0022034512467352$
33 Thierauf J, Veit JA and Hess J: Epithelial-to-mesenchymal transition in the pathogenesis and therapy of head and neck cancer. Cancers (Basel) 9(7), 2017. PMID: 28671620. DOI: 10.3390/cancers 9070076

34 Morris JC, Tan AR, Olencki TE, Shapiro GI, Dezube BJ, Reiss M, Hsu FJ, Berzofsky JA and Lawrence DP: Phase I study of GC1008 (fresolimumab): a human anti-transforming growth factor-beta (TGFbeta) monoclonal antibody in patients with advanced malignant melanoma or renal cell carcinoma. PLoS One 9(3): e90353, 2014. PMID: 24618589. DOI: 10.1371/ journal.pone.0090353

35 Wang C, Huang H, Huang Z, Wang A, Chen X, Huang L, Zhou $\mathrm{X}$ and Liu $\mathrm{X}$ : Tumor budding correlates with poor prognosis and epithelial-mesenchymal transition in tongue squamous cell carcinoma. J Oral Pathol Med 40(7): 545-551, 2011. PMID: 21481005. DOI: 10.1111/j.1600-0714.2011.01041.x

36 Almangush A, Pirinen M, Heikkinen I, Makitie AA, Salo T and Leivo I: Tumour budding in oral squamous cell carcinoma: a meta-analysis. Br J Cancer 118(4): 577-586, 2018. PMID: 29190636. DOI: $10.1038 /$ bjc.2017.425
Received September 25, 2019

Revised October 15, 2019

Accepted October 17, 2019 